\title{
PATTERNS OF PESTICIDES POISONING AMONG CHILDREN IN CAIRO, EGYPT: A RETROSPECTIVE STUDY
}

\author{
Said m. Abul-nasr; Naglaa f. Mahmoud; Marwa i. Nasr; Amal s. Mahmoud \\ Department of forensic medicine and clinical toxicology, faculty of medicine, cairo \\ university, cairo, egypt
}

\begin{abstract}
:
Acute poisoning represents one of the most common medical emergencies in childhood; Children are uniquely vulnerable to uptake and adverse effects of pesticides because of developmental, dietary, and physiologic factors. This study was designed to describe the pattern of childhood poisoning with pesticides in order to take up appropriate planning and prevention techniques. This retrospective study included 280 pediatric cases under the age of 18 years with acute pesticide poisoning admitted to National Center for Environmental \& Clinical Toxicological Research (NECTR), Cairo University Hospitals during the period from January to December 2014. Complete demographic and clinical data were recorded and analyzed. Results revealed that, Incidence was more common among Females than males $(65.4 \%$ versus $34.6 \%$ ). Majority of cases were in adolescent age group (12-18yrs) and constituted (63.2\%). Suicidal attempts accounted for the highest percent $(52.5 \%)$ of poisoning. The presenting symptoms were muscarinic manifestations in $(51.4 \%)$. Recovered and discharged cases accounted for $(88.9 \%)$, (7.2\%) left against medical advice, $(2.9 \%)$ complicated and referred to the suitable specialty, (1.1\%) complicated and died. The period of hospitalization was less than 24 hrs in the majority of cases $(78.9 \%)$ compared to $(18.9 \%)$ were hospitalized more than 24 hrs. Effective health promotion programs for parents and caregivers regarding poisoning hazards are needed to increase awareness and reduce the incidence of poisoning among children.

Key words: poisoning, pesticides, children, Egypt.

INTRODUCTION

Childhood poisoning represents a major public health problem worldwide that can be prevented through educational efforts. Poisoning might occur accidental or intentional whether suicidal or homicidal. Various drugs and chemical compounds have been implicated in children poisoning such as kerosene, chlorine, acetyl cholinesterase inhibitor insecticides as well as carbon monoxide. Among the risk factors for unintentional poisoning in children under 5 years are: (1) Accessibility to hazardous chemicals and medicines due to unsafe storage. (2) Aggressive child's behavior. (3) Low socioeconomic status. (4) Low

level of mother's education (Seif. et al., 2016).

Pesticides stand as one of the important agents of childhood poisoning. Children are uniquely vulnerable to both the uptake and the adverse effects of pesticides due to developmental, dietary and physiologic factors. According to US National Poison Data System reports, pesticides ranked eighth in category of substances most frequently involved in pediatric exposure (Mowry et al., 2015).

With the progress in the industrial and agricultural field and advances in medical sciences a great number of pesticides have become available, which on exposure may produce
\end{abstract}


considerable toxicity. Unintentional poisoning is more common in children, whereas suicidal ingestion is more common in young adults (Won et al., 2014) One third of the world's suicides is attributed to Pesticide self-poisoning. The proportion of all suicides by pesticides varies from $4 \%$ in the European area to over $50 \%$ in the Western Pacific region (Das, 2007).

Knowing the nature, epidemiology and severity of poisoning in order to take appropriate preventive measures is of paramount importance. Studies of this nature will be a useful tool for planning and management of critically ill acute poisoning patients.

The present study was carried out with the objective to investigate the pattern of acute pesticides poisoning among pediatrics under the age of 18 years in NECTR during 2014, Regarding their demographics, prevalence, clinical picture, management and outcome.

\section{SUBJECTS \& METHODS}

\subsection{Collection of Data:}

Data was collected from files of poison center cases who were admitted in the period of January to December 2014. The sample included 280 patients below 18 years. Diagnosis of poisoning was made according to history of the patient or his relatives or clinical examination.

Exclusion Criteria: We exclude Adults (more than 18 years old) and Patients with other medication toxicity. Studied Parameters: The demographic and poisoning data including age, sex, season, implicated pesticide type, mode of poisoning, route of poisoning, presenting symptoms, and signs, laboratory investigations, duration of hospitalization, Data regarding management and final outcome were recorded.

Ethical Clearance: The study protocol was approved by the Ethical Committee in kasr alaini hospital Cairo University. Confidentiality on the content of the medical records was maintained. The information was only utilized by the investigators for the research purpose.

\section{Statistical Analysis}

The obtained data were recorded and statistically analyzed Comparison of quantitative variables was done using Mann-Whitney test. For comparing categorical data, Chi square test was performed. A probability value (Pvalue) less than 0.05 was considered statistically significant (Chan, 2003).

\section{RESULTS}

The total number of pesticides poisoned children during this period was 280 of both sexes (97 males and 183 females). Cases were classified into 4 groups according to their ages; infancy (0-2 y), preschool (2-6 y), school age (6-12 y) and adolescent (1218y). Table (1) revealed that the majority of cases were in adolescent age group 177 (63.2\%). Preschool age group represented 57 cases (20.3\%). Female gender achieved a higher percentage than male $(65.4 \%$ versus $34.6 \%$ ). Suicidal mode of toxicity accounted for the highest percent $(52.5 \%)$ of poisoning. The majority of cases $(97.1 \%)$ were exposed by oral route while dermal and inhalation route represented $(5 \& 3 \%)$ respectively. The majority of cases 237 (84.6\%) were due to organophosphate toxicity. Zinc phosphide and anticoagulants rodenticides accounted for $(8.9 \%$ \& $5.3 \%$ ) respectively of the implicated poisoning causes. 
Table (1): Demographic and Poisoning Data of the Studied Cases.

\begin{tabular}{|l|l|l|}
\hline Variable & No. & Percent. \\
\hline Age & 28 & $10 \%$ \\
Infancy (0-2 ys) & 57 & $20.3 \%$ \\
Preschool (2-6 ys) & 18 & $6.4 \%$ \\
School (6-12 ys) & 177 & $63.2 \%$ \\
Adolescent (12-18 ys) & & \\
Sex & 97 & $34.6 \%$ \\
Male & 183 & $65.4 \%$ \\
Female & & \\
Mode & 126 & $45 \%$ \\
Accidental & 147 & $52.5 \%$ \\
Suicidal & 7 & $2.5 \%$ \\
Missed data & & \\
Route & 272 & $97.1 \%$ \\
Oral & 5 & $1.7 \%$ \\
Dermal & 3 & $1 \%$ \\
Inhalation & & \\
Implicated pesticides type & 237 & $84.6 \%$ \\
Organophosphate & 3 & $1 \%$ \\
Pyrethroids & 25 & $8.9 \%$ \\
Zinc phosphide & 15 & $5.3 \%$ \\
Anticoagualnts & \\
\hline
\end{tabular}

This study showed that most of suicidal poisoning $(98.0 \%)$ was recorded among adolescent females $(87.7 \%)$. On the other hand, accidental poisoning contributed to $(45.2 \%)$ of poisoning

among preschool age group. A significant difference was observed between age and sex as regard mode of toxicity where $\mathrm{P}$-value $<\mathbf{0 . 0 0 1}$.

Table (2): Distribution of by age, Sex and Mode of toxicity.

\begin{tabular}{|l|l|l|l|}
\hline Variable & $\begin{array}{l}\text { Suicidal No } \\
(\mathbf{\%})\end{array}$ & $\begin{array}{l}\text { Accidental } \\
\text { No (\%) }\end{array}$ & P-Val \\
\hline Age & $0(0.0 \%)$ & $28(22.2 \%)$ & \\
Infancy (0-2 ys) & $0(0.0 \%)$ & $57(45.2 \%)$ & $<\mathbf{0 . 0 0 1}$ \\
Preschool (2-6 ys) & $3(2.0 \%)$ & $14(11.1 \%)$ & \\
School (6-12 ys) & $144(98.0 \%)$ & $27(21.4 \%)$ & \\
Adolescent (12-18 & & $75(59.5 \%)$ & $<\mathbf{0 . 0 0 1}$ \\
Sex & $18(12.2 \%)$ & $51(40.7 \%)$ & \\
\hline Male & $129(87.7 \%)$ & $\mathbf{1 2 6}$ & \\
Female & $\mathbf{1 4 7}$ & No:Number ys: years \\
Total & \multicolumn{4}{|l}{} \\
\hline
\end{tabular}

Table (3) showed that the highest percentage of pediatric poisoning occurred in autumn $(43.9 \%)$ followed by summer season $(24.6 \%)$. 
Table (3): Distribution of Cases regarding seasonal variation

\begin{tabular}{|c|c|c|}
\hline Season & Number & Percentage (\%) \\
\hline Spring & 45 & $16.1 \%$ \\
\hline Summer & 69 & $24.6 \%$ \\
\hline Autumn & 123 & $43.9 \%$ \\
\hline Winter & 43 & $15.4 \%$ \\
\hline Total & 280 & $100 \%$ \\
\hline
\end{tabular}

Table (4): Distribution of cases according to the clinical manifestation and PCE level

\begin{tabular}{|l|l|l|}
\hline Variable & Number & Percent \\
\hline Clinical Manifestations & & \\
\hline Muscarinic manifestation & 144 & $51.4 \%$ \\
Nicotinic manifestation & 47 & $16.8 \%$ \\
Missed data & 89 & $31.8 \%$ \\
PCE on entry & & \\
Normal & 78 & $27.8 \%$ \\
Depressed level & 158 & $56.4 \%$ \\
Missed data & 44 & $15.7 \%$ \\
\hline
\end{tabular}

PCE: Pseudocholine esterase

The presenting symptoms were classic muscarinic manifestations (nausea, vomiting, abdominal pain and pinpoint pupil) in 144 cases $(51.4 \%)$, 47cases $(16.8 \%)$ presented with nicotinic manifestations in the form of muscle fasciculation, palpitation ,convulsion and decreased level of consciousness and 89 cases $(31.8 \%)$ were unrecorded. Acetyl cholinesterase was depressed (ranged from mild to moderate depression) in $56.4 \%$ of the cases while it was within normal range in $27.8 \%$ and not recorded in $15.7 \%$ of the cases as revealed in table (4). Figure (1) showed that $(63.7 \%)$ who had mild depression of PCE1 came with muscarinic manifestations, 36 cases $(22.9 \%)$ presented with nicotinic manifestations, and 21 cases (13.4\%) were unrecorded. However, only 1 case $(100 \%)$ who had moderate depression in PCE1 came with nicotinic manifestations, while no reported cases with severe depression of PCE. As regard the treatment given. Table (5) revealed that the majority of cases 114 $(40.7 \%)$ treated with gastric lavage \& charcoal. Activated charcoal was given in $79(28.2 \%)$. Furthermore, $(58.9 \%)$ of the cases received atropine and $56.4 \%$ treated with oximes and $52.1 \%$ received both atropine and oximes. It was found that 248 cases $(88.6 \%)$ completely recovered, 20 cases $(7.1 \%)$ leaved against medical advice (LAMA), 8 cases $(2.8 \%)$ had complications and referred and 3 cases (1.1\%) had complications and died. 
Table (5): Distribution of cases according to the received intervention \&fate

\begin{tabular}{|l|l|l|}
\hline Intervention & Number & Percent \\
\hline Decontamination & & \\
\hline Gastric lavage(GL) & 14 & $5 \%$ \\
Activated charcoal & 79 & $28.2 \%$ \\
(AC) & 114 & $40.7 \%$ \\
GL+ A.C & 73 & $26 \%$ \\
No decontamination & & \\
\hline Antidotes & & \\
Atropine & 165 & $58.9 \%$ \\
Oximes & 158 & $56.4 \%$ \\
Atropine + oxime & 146 & $52.1 \%$ \\
\hline Fate & & \\
Recovery & 248 & $88.5 \%$ \\
LAMA & 20 & $7.1 \%$ \\
Complicated & 8 & $2.8 \%$ \\
Complicated\& died & 3 & $1.1 \%$ \\
Missed & 1 & $0.4 \%$ \\
\hline
\end{tabular}

LAMA: Leaving Against Medical Advice

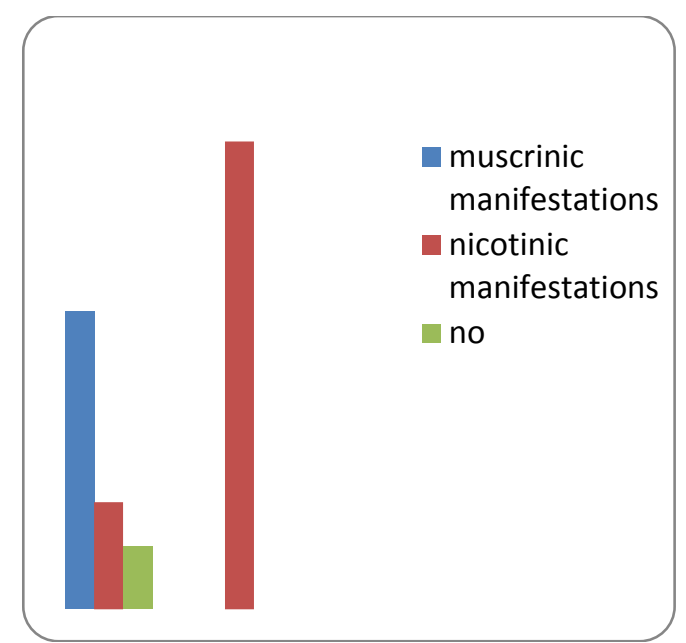

Figure (1): Bar chart showing distribution of cases according toPCE1 level on entry and symptoms type.

It was clear that time elapsed till hospital arrival affect the prognosis of the cases as observed in figure (2) that $(95.3 \%)$ of the recovered cases had elapsed time less than 6 hours before arrival to the center. However, in complicated and referred cases, 6 cases (75\%) delayed from 7 to 24 hours, while in complicated and died cases, 3 cases $(100 \%)$ delayed $>24$ hours. PValue was significant. Figure (3) showed the period of hospitalization was less than $24 \mathrm{hrs}$ in the majority of cases $(78.9 \%)$ compared to $(18.9 \%)$ were hospitalized more than $24 \mathrm{hrs}$. 


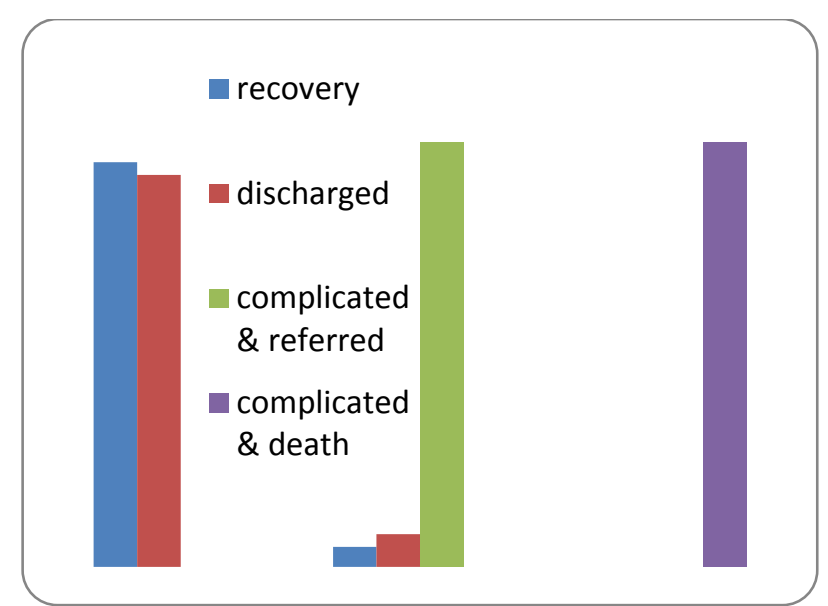

Figure (2): Bar chart showing distribution of cases by delay time and prognosis

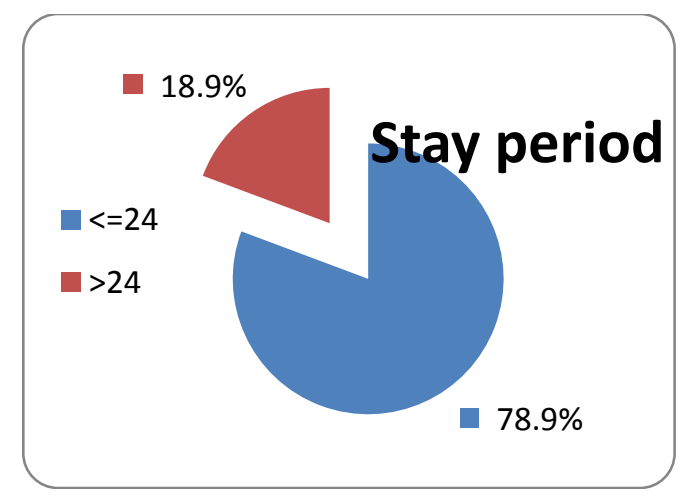

Figure. (3): Bar chart showing distribution of cases by period of stay.

\section{DISCUSSION}

Acute poisoning is considered one of the most common medical emergencies in childhood. The medical records for 280 children presented at NECTR, Cairo University Hospitals were retrieved and studied. Unfortunately there was some missing data it will give a clear ,accurate data analysis regarding mode of poisoning in $(7$ cases) and type of clinical manifestations in (89 cases). In the present study patients belonging to age group 12-18 years represented the largest proportion $(63.2 \%)$ of the studied cases. This result was in agreement with Abdel Rahman \& Nashwa et al. (2011); Dhaval et al. (2011) and Kar et al. (2011) who stated that the majority of cases were teenagers and younger adults. During the teen years, boys and girls face the difficulties of transition into adulthood due to hormonal, environmental and physiological factors which make this period anxious and unsettling period. On the contrary, Seif. Et al. (2016).and Raed et al. (2012) have concluded that most of cases were children less than 6 and 5 years. They further stated that widespread availability and use of organophosphates, and the lack of regulation and safety packaging are high risk for accidental exposure in those age group.

Females accounted for the majority of cases $(65.4 \%)$ in comparison to males $(34.6 \%)$. The female: male ratio is 1.89: 1 . These results are coincident with the results reached by Paudyal (2008), Abdel Rahman et al. (2011) and Kar et al. (2011). The higher rate in females can be explained by their 
vulnerability to different stresses which lead them to commit suicide by less violent methods, e.g. Ingestion of drugs or toxins. However, Nadia et al. (2008) and Raed et al. (2012) found that males are more exposed than females, as males are more active and having more outdoor activity. Alexandre et al. (2008) also showed that men were more vulnerable to commit suicide with organophosphate and carbamate insecticides complicated with most serious consequences.

In this study, the majority of cases $(52.5 \%)$ were due to suicidal exposure, while $(45 \%)$ were due to accidental exposure. These results are coincident with the results declared by Amarnath et al. (2012) and Sharda et al. (2013). Furthermore, most of suicidal cases, in the present study, were among adolescents. Adolescence has been traditionally viewed as a period of stress and storm. Rates of depression in teens are equivalent to those in adults, and suicide deaths are considered the 3rd most common cause of death in adolescence (Mary et al 2004). However, these results disagree with the study of Alexandre et al. (2008), which was performed on cases received over (12 years), and found that suicidal attempts were $48.6 \%$.

In the present study, oral ingestion represented the most common route implicated in the majority of cases (97.1\%). These results are in agreement with Murat \& Muhammed (2001) and Sharda et al. (2013). This could be explained by oral ingestion is the main route of exposure in suicidal and accidental ingestion.

The present study revealed that the majority of cases were due to organophosphate toxicity (84.6\%), while only $(8.9 \%)$ were poisoned by
Zn- phosphide, and (5.4\%) with rodenticides (anticoagulants). These results are in line with Chi-Feng et al. (2012) who stated that the most common pesticide poisonings were organophosphates and paraquat. Furthermore Alexandre et al. (2008) also concluded that the most common type of pesticide implicated in poisonings was organophosphates. Also, Kar et al. (2011) reported that Methyl Parathion showed the highest consumption $(64.62 \%)$ for suicide at Nepal.

On the other hand, these results disagree with the results obtained by Sharda et al. (2013), who found that most of cases were due to household products $(59.3 \%)$, pyrethroids (26.23\%), followed by rodenticides $(17.06 \%)$.This difference could be explained by the widespread availability of cheap pesticides, lack of regulation and safety packaging while dealing with pesticides compounds in our community .

In this study, the peak incidence of pesticide toxicity occurred during autumn months (43.9\%). As psychological changes can be affected by seasonal factors and resulted in suicide. There is also a physiological stress that result from the low ambient temperatures" during autumn and winter, from which suicidal ideations are considered to occur (Van de Wolfshaar et al., 2008).

These results disagree with Won et al.(2014) who after his study on rural area population concluded that a The proportion of acute pesticide poisoning cases was highest in summer and lowest in winter on contrary to our result as the majority of patients were from urban areas $(79.3 \%$ compared to $20 \%$ from rural area ). He further stated 
that summer is the main harvesting season, and the easy availability of the different types of pesticides increases the incidence.

In this study, the majority of patients $(51.4 \%)$ have muscarinic manifestations in the form of nausea, vomiting, diarrhea, pinpoint pupil (ppp) and disturbed conscious level (DCL) ,while only $(16.8 \%)$ have nicotinic manifestations in the form of fasciculation and palpitations this could be explained by, severity of poisoning in most of cases ranged from mild to moderate poisoning $(66.9 \%)$ also duration of exposure in the majority of cases was limited as the mean delay period to admission in this study was 2.9 hours .These results are in agreement with Murat \& Muhammed. (2001) and John et al. (2014) who stated that majority of patients were manifested with abdominal pain, nausea, vomiting, salivation, abdominal pain and miosis; while central muscarinic effects resulted in symptoms such as confusion, convulsions and coma (John et al., 2014). This could be explained by the effect of increased levels of acetylcholine neurotransmitter at the muscarinic receptors.

In the current study, the majority of cases $56.4 \%$ have depressed levels of the enzyme (mild depression in $99.4 \%$ of cases and moderate depression in only $0.6 \%$ of cases ), while $27.8 \%$ of cases have normal level of PCE. These results coincide with Nadia et al. (2008), who showed that $56 \%$ of cases had decreased levels of serum cholinesterase. Furthermore, the study of Abd El- Rahman (2009) showed that about $89 \%$ of cases had depressed levels of the enzyme.
In this study, $40.7 \%$ of cases were treated by both gastric lavage and activated charcoal, $5 \%$ of cases had gastric lavage only, while $28.2 \%$ of cases received charcoal only as majority of cases $56.4 \%$ have depressed levels of the enzyme and most of the patients $(51.4 \%)$ have muscarinic manifestations in the form of nausea, vomiting, diarrhea, pinpoint pupil (ppp) and disturbed conscious level (DCL) ,while only $(16.8 \%)$ have nicotinic manifestations. In agreement with these results, Alexandre et al. (2008) stated that gastric lavage and charcoal administration were required for $39 \%$ and $28 \%$ of the patients, respectively. On the other hand Seif. Et al. (2016) showed that gastric lavage was done for the majority of patients (94.4\%).Sungur \& Guven, (2001) also agree with these results.

In the present study, the majority of cases recovered $(88.6 \%)$, while $(7.1 \%)$ leaved against medical advice. These results are in agreement with Nadia et al. (2008); Abdel Rahman \& Nashwa (2011); Dhaval et al. (2011) and Raed et al., (2012). As regards to cases leaved against medical advice, most of them discharged before $48 \mathrm{hrs}$ on personal consent for social or financial reasons, most of them were completely cured as revealed on follow up in the outpatient clinic. Death was recorded only in $1.1 \%$ of cases due to delay in reaching the hospital, deterioration of the patient's general condition, and development of pulmonary complications. Depression was the commonest residual outcome in most cases of intentional poisoning, and these needed psychological assessment and follow up with a specialist.

In this study, the majority of cases $(78.9 \%)$ stayed less than 24 hours, 
while only $(18.9 \%)$ of cases admitted more than 24 hours.as the severity of poisoning in most of cases ranged from mild to moderate poisoning $(66.9 \%)$. This is in accordance with Won et al.(2014) who stated that The majority of hospital stays were 1 day in length, and 34 children had visited a hospital more than once. While Proudfoot (2009) and Abdel Rahman \& Nashwa. (2011) concluded that the majority of cases were admitted more than 24 hours.

\section{CONCLUSION \& RECOMMENDATIONS}

This study revealed that Most of the poisonings were due to suicidal ingestions by adolescent females. Antidote administration and good supportive care are the cornerstone of management lines for pediatric poisoning by pesticides. We demonstrated the magnitude of acute pesticide poisoning among children in Great Cairo -Egypt and its epidemiological characteristics. Intensive intervention efforts such as appropriate at-home storage or management of pesticides and strict regulation of toxic pesticides used as household products are needed to reduce acute pesticide poisoning in children. Since intentional selfpoisoning is often impulsive and simplified by easy availability of the poison, a considerable percent of selfpoisoning by pesticides can be prevented by limiting its access. One limitation of this study is the lack of detailed information related to childhood poisoning, such as mode of poisoning in ( 7 cases) and type of clinical manifestations in (89 cases), individual agents, intention, family members and educational level of parents, which hinders further analysis. So improving documentation, proper \& complete medical record-keeping are highly recommended for a better information access and accurate assessment. The epidemiological pattern of childhood poisonings should be further evaluated by prospectively well designed multi-center studies throughout our country.

\section{REFERENCES}

Abd El-Rahman, E.; Alaa, S. E. ; Mohammed, S.A.; and Sayed, M. B. (2009): Clinical findings and cholinesterase levels in children of organophosphates and carbamates poisoning. Eur. J. Pediatr., 168(8):951-956.

Abdel Rahman, M. E and Na s h w a, M. E. (2011): Zinc phosphide toxicity with a trial of tranexamic acid in its management. J. Adv. Res., (2): 149-156.

Alexandre, F.; Elisangela, M.; Mauricio, Y. and Magda, L. F. (2008): Organophosphate and carbamate poisonings in the northwest of Paraná state, Brazil from 1994 to 2005: clinical and epidemiological aspects. Braz. J. Pharm. Sci., 44(3): 407-415.

Amarnath, M.; Shukla, S.K.; Yadav, M.K. and Gupta, A.K. (2012): Epidemiological Study of Medicolegal Organophosphorus Poisoning in Central Region of Nepal J. For. Res., 3:167-170.

Chan, T.Y.H. (2003): Biostatistics102: Quantitative Data Parametric \& Non-parametric Tests. Singapore Med. J., 44(8): 391-396.

Das, R.K. (2007): Epidemiology of insecticide poisoning at A.I.I.M.S Emergency Services and role of its 
detection by gas liquid chromatography in diagnosis. Medico update; 7:49-60.

Dhaval, J .; Patel, P . And T e k a d e, R. (2011): Profile of Organophosphorus Poisoning at Maharani Hospital, Jagdalpur, and Chhattisgarh: Three Years Study. J. Indian Acad. For. Med., AprilJune, 33(2): 102- 105.

John, V. P.; Thomas, I. S. and John, L. M. (2014): Clinical features of organophosphate poisoning: A review of different classification systems and approaches. Indian J. Crit. Care Med., 18(11): 735-745.

Kar, S.M.; Sidartha, T. And Rashant, A. (2011): An Epidemiological study of Organophosphorus Poisoning at Manipal Teaching Hospital, Pokhara, Nepal. J. Indian. Acad. For. Med., 32(2): 108-109.

Mary, M.G.; Prachi, S.; and Neil, W. B. (2004): Assessment and interviewing Psychologic disorders. In: Kliegman, R.; Behrman; Jenson. Stanton; Richard, E. (eds.): NELSON, 19th edition, vol 2, chap 19, Elsevier Inc. Philadelphia, 101-161.

Mowry, J.B, ;Spyker, D.A; Brooks, D.E; McMillan, $N$ and Schauben, J.L.( 2015) : 2014 annual report of the American Association of Poison Control Centers' National Poison Data System (NPDS): 32nd annual report. Clin Toxicol; 53(10): 962-1147.

Murat, S. and Muhammed, G. (2001): Intensive care management of organophosphate insecticide Poisoning, Crit. Care, 5:211-215.

Nadia, A. A.; Jamal, A.,; Ejaz, A. K.; Rukhsana, A. S. and Rashid,
D. (2008): acute organophosphate insecticide poisoning. J. Surg. Pakistan (International) 13 (2):7174.

Paudyal,

B.P.

(2008):

Organophosphorus Poisoning. J Nepal Med Assoc.47 (172):251258.

Proudfoot, A.T. (2009): Aluminium and zinc phosphide poisoning. Clin. Toxicol. (Phila.), 47:89-100.

Raed, M .A.; Mahmoud, T. E.; Ramadan, A. F.; Hoda, F. A. and Amr, S. M. (2012): Risk factors of acute poisoning among children: A study at a poisoning unit of a university hospital in Egypt, South East Asia J. Public Health, 2(2):41-47.

Seif .E ; Gomaa.R ; Eisa .M : Retrospective Study of Acute Poisoning in Children under 5 Years Old Admitted to Alexandria Poison. World J. of Prevent. Med., 2016, Vol. 4, No. 2, 32-39.

Sharda, S. P.; Scientist, A. S.; Scientist, N. H.; Scientist, Y. and K u m a r , G. (2013): Pesticide poisoning trend analysis of 13 years: A retrospective study based on telephone calls at the National Poisons Information Centre, All India Institute of Medical Sciences. New Delhi J. For. Legal Med., 22 (2014): 57-61.

Sungur, M. and Güven, M. (2001): Intensive care management $\mathrm{o}$ organophosphate insecticide poisoning. Crit. Care, 5(4):211215.

Van der.; Wolfshaar, K. E.; De Roos, A. M. and Persson, L. (2008): "Population feedback after successful invasion leads to ecological suicide in seasonal 
environments". Ecology, 89: 259268.

Won, J. L; Yousun ,K.o; and Eun, S. C.(2014) : Acute Pesticide Poisoning among Children in South
Korea: Findings from National Health Insurance Claims Data, 2006-200. J OF trop. pediat., vol. 60 , no. 1 . 


\section{أنماط التسمم بالمبيدات بين الاطفال في القاهرة ، مصر ، مدر : دراسة استعادية

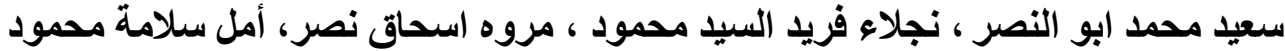

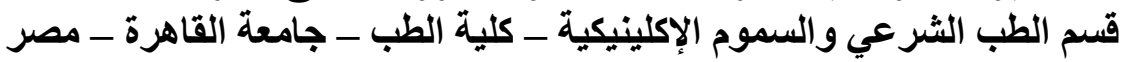

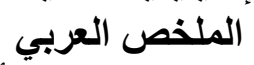

يمثل التسمم الحاد واحدة من حالات الطوارئ الطبية الأكثر شيو عا في مرحلة الطفولة. يعتبر الأطفال

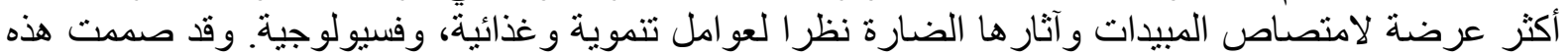

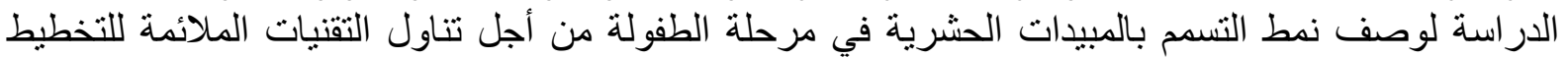

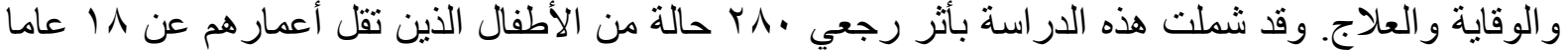

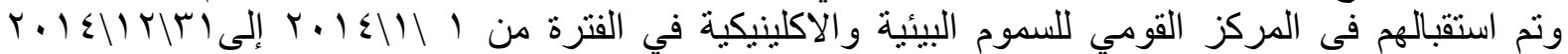

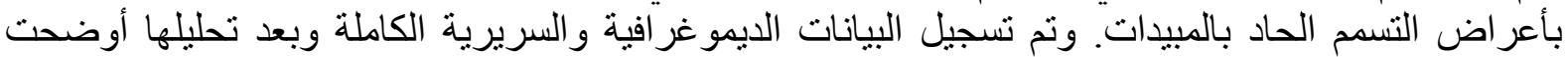

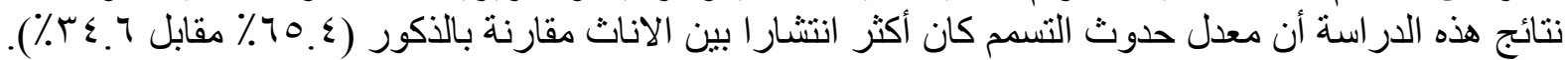

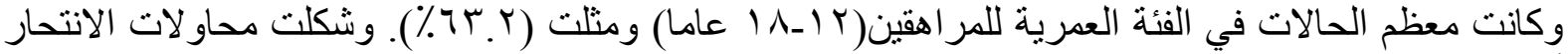

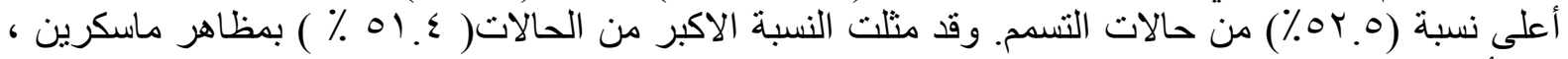

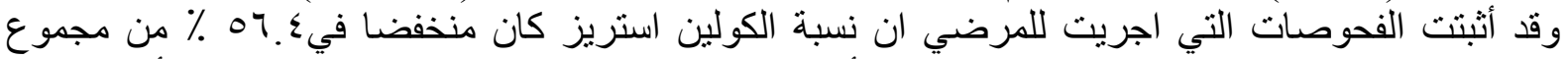

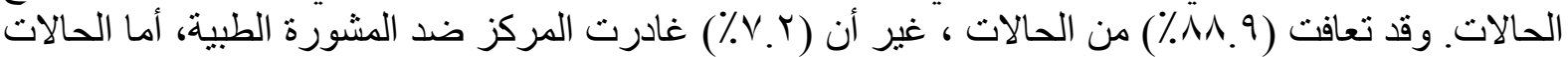

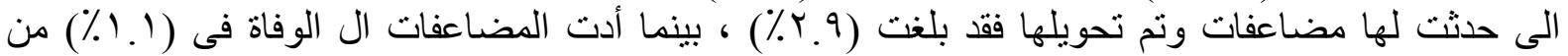

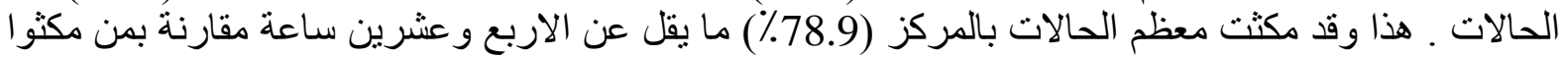

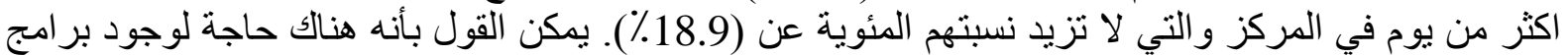

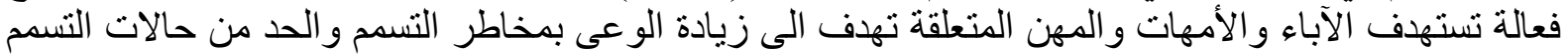

